\title{
Evaluation of Osteopenia and Osteoporosis among Female Doctors
}

\author{
SETARA BINTE KASEM, FERDOUSI BEGUM, SHAIKH ABDUR RAZZAQUE, \\ RAISAADIBA, SELMAANIKA
}

\begin{abstract}
Osteopenia and Osteoporosis are increasing health care problems due to increased life expectancy. Women are specially vulnerable to osteoporosis at their later ages of lives. Among the working population of Bangladesh, female doctors make a big contribution for nation, so focusing on their wellbeing is very much important. In this study BMD (Bone Mineral density) were measured among 80 female doctors .

Objective: To find out the Bone Mineral Density (BMD) among working female doctors of Bangladesh.

Materials and Methods: A cross sectional study was conducted on 80 female doctors aged between 25-80 years at their reproductive, premenopausal and postmenopausal age group, at a conference venue over a period of two days. Measurement of bone mineral density was done by quantitative ultrasound densitometry ${ }^{1}$.

Result: Majority of women were between 30-64 years of age; 71(88.75\%) women had normal BMD, 9(11.25\%) women had osteopenia and none of them had osteoporosis. Among women with age between 25-44 years age (total 30) none was suffering from osteopenia or osteoporosis. Between 45-64 years (total 47), 8(17.02\%) were suffering from osteopenia and between 65-80 years (total 3), 1(33.33\%) was suffering from osteopenia. Nobody had osteoporosis.

Conclusion: Among the working female gynaecologists of Bangladesh there were no osteopenia or osteoporosis in reproductive and premenopausal (25-44 years) age group. Only $17.04 \%$ of premenopausal women and women at early menopause ( $45-64$ years) suffer from osteopenia and 33.33\% of women at late menopause (65-80years) had osteopenia. None had osteoporosis.
\end{abstract}

Keywords: Female doctor, BMD, Osteopenia, Osteoporosis.

\section{Introduction}

Osteoporosis has been defined as a disease characterized by low bone mass and microarchitectural deterioration of bone tissue, which leads to enhanced bone fragility and increased fracture risk $^{1,2}$. Low bone mass, defined by bone mineral density (BMD) values in the osteopenic range, can progress to osteoporosis if left untreated ${ }^{3}$.
Osteoporosis represents a major public health concern worldwide. In the United States, an estimated 10 million adults aged 50 years or more had osteoporosis, with more than 5 million having osteoporosis of the femoral neck, including 4.5 million women and 800,000 men $^{4}$.

Beginning with menopause, women sustain an accelerated period of bone loss because

1. Dr. Setara Binte Kasem, Associate Professor (Gynae \& Obstetrics), Dhaka Medical College.

2. Prof. Ferdousi Begum, Professor and Head of the Department (Gynae \& Obstetrics), Ibrahim Medical College \& BIRDEM General Hospital.

3. Dr. Shaikh Abdur Razzaque, Professor (Paediatric Cardiology), National institute of Cardiovascular diseases.

4. Dr. Raisa Adiba, Honorary Medical Officer, Dhaka Medical Hospital.

5. Dr. Selma Anika, 4th year student, Bangladesh Medical College.

Address of Correspondence: Dr. Setara Binte Kasem, Associate Professor (Gynae\&Obs), Dhaka Medical College. E mail: dr.setaraa@gmail.com., Mob: 01552314895 
approximately 5-7 years after menopause, they may lose bone at the rate of $3-5 \%$ per year. It has been estimated that approximately $75 \%$ of bone lost in the years after menopause may be related to estrogen deficiency rather than age ${ }^{5}$. Low education and being housewife were shown to be risk factors of osteoporosis. The reason probably is the effect of education on lifestyle, nutrition and economic status $^{6}$.

So, the aim of the present study was to evaluate the prevalence and age related factors of decreased bone mass density among reproductive, pre- and postmenopausal educated working women in order to delay or prevent osteoporosis in old age.

Currently bone is mainly assessed using one of the X-ray densitometry methods, for example with dual energy $x$-ray absorptiometry. While providing reasonable indications of bone integrity, these $X-$ ray densitometric techniques are relatively expensive, expose the patient to ionizing radiation and are not able to characterize all of the variability observed in bone strength or accurately predict the occurrence of fractures in individuals. As is well known, mass based methods do not provide any information on other factors known to be associated with bone strength, such as bone architecture and tissue quality ${ }^{7,8}$. These various shortcomings of current densitometric techniques have led to the search for more effective bone assessment methods. One such technique is based on ultrasound, which offers several potential advantages for assessing bone strength and fracture risk. Ultrasound is non-ionizing and relatively easy to generate and detect ${ }^{9}$.

\section{Materials and Methods}

This cross sectional study was carried out on a conference venue at Hotel Regency International, Dhaka $8^{\text {th }}$ and $9^{\text {th }}$ may 2015 . Eighty female doctors were included in this study. Their age range was between 26-79 years. They were all from higher middle and higher socioeconomic condition. The study was done by a new ultrasound device for noninvasive assessment of bone. The device, known as the QRT 2000- for Quantitative Real Time-is entirely self contained, portable, and handheld, and is powered by rechargeable batteries. ${ }^{9}$ Here BMD of the calcaneus bone were determined. Informed written consent was obtained from all study subjects.

For determination of osteoporosis, BMD level (according to WHO) is:T level- Normal: -1 to +1 , Osteopenia: -2.5 to -1 , Osteoporosis: $<-2.5$, Severe osteoporosis: $<-2.5$ and history of one or more bone fracture.

\section{Results}

During the study period total of 80 female doctors were included.

Table-I

Distribution of study subjects according to age $(N=80)$

\begin{tabular}{lc}
\hline Age in years & No of women \\
\hline $25-29$ & $2(2.5 \%)$ \\
$30-34$ & $5(6.25 \%)$ \\
$35-39$ & $11(13.75 \%)$ \\
$40-44$ & $12=(15 \%)$ \\
$45-49$ & $14=(17.5 \%)$ \\
$50-54$ & $12=(15 \%)$ \\
$55-59$ & $15=(18.75 \%)$ \\
$60-64$ & $6(7.5 \%)$ \\
$65-69$ & $1(1.25 \%)$ \\
$70-74$ & $1(1.25 \%)$ \\
$75-80$ & $1(1.25 \%)$ \\
\hline
\end{tabular}

Majority of women were between $30-64$ years (table 1).

Table II

Distribution of osteopenic and osteoporotic women according to BMD status

BMDlevel among the study subjects

\begin{tabular}{lc}
\hline Normal & $71(88.75 \%)$ \\
Osteopenia & $09(11.25 \%)$ \\
Osteoporosis & $00(0 \%)$ \\
\hline
\end{tabular}

Among the sample majority i.e.71(88.75\%) had normal BMD, 9(11.25\%) had osteopenia and none had osteoporosis (table - II). 
Table III

Distribution of study subjects according to age and BMD level

\begin{tabular}{lccc}
\hline Age in years & No of Women & No of normal women & No of osteopenic women \\
\hline $25-44$ & 30 & $30(100 \%)$ & Nil $(0 \%)$ \\
$45-64$ & 47 & $39(82.98 \%)$ & $8(17.02 \%)$ \\
$65-80$ & 3 & $2(66.67 \%)$ & $1(33.33 \%)$ \\
\hline
\end{tabular}

No women of age group between 25-44 years was suffering from osteopenia or osteoporosis. Between $45-64$ years of age $8(17.02 \%)$ and between $65-80$ years of age $1(33.33 \%)$ had osteopenia (table - 3 ).

\section{Discussion:}

Bone Mineral Density (BMD) is the primary determinant of skeletal fragility, as such, plays a central role in the diagnosis of osteoporosis ${ }^{2}$. There is considerable evidence that as BMD decreases, risk of fracture increases. ${ }^{11-14}$ Osteoporosis is an increasing health care problem, with a Caucasian women having a $30 \%$ lifetime risk for sustaining an osteoporosis related fracture ${ }^{15}$.

Low bone mass represents an increasing health risk and burden. Half of fragility fractures occur in osteopenic women underscoring the need for treatments reducing fracture risk ${ }^{3}$. Low bone mass, defined by bone mineral density (BMD) values in the osteopenic range, can progress to osteoporosis if left untreated. Additionally, it has recently become apparent that osteopenia is a significant risk factor for fragility fractures in older women ${ }^{3}$. Osteopenia is common in postmenopausal women and contributes to the increased risk of fracture in this population. There is a need for clinical data examining both fracture risk in women with T-scores in the osteopenic range and the evidence for an effect of treatment on reducing the risk ${ }^{3}$.

In the present study, both premenopausal and postmenopausal women were included. They were all from higher and higher middle socioeconomic condition. Out of 80 women $71(88.75 \%)$ women had normal BMD and 9(11.25\%) women were suffering from osteopenia. Women, age ranged between 25 to 44 years had normal BMD. Among 45 to 64 years women, 8(17.02\%) wereosteopenic and 39(82.98\%) were with normal BMD.Among 65 to 80 years women I(33.33\%) women was osteopenic,2(66.67\%) women were with normal BMD.Osteopenia increased significantly with age which could be attributed to the decreased level of estrogen hormone at old age, with consequent negative effect on bone ${ }^{1}$

The prevalence of osteoporosis in the Swedish females increased with age. Approximately $21 \%$ of women aged $50-84$ years were classified as having osteoporosis compared to $50 \%$ women aged $80-84$ years. In women aged 50-54 years, the number of individuals with low bone mass was six-fold higher than the number of those with osteoporosis. These results coincide with Demiret al. who reported the prevalence of osteopenia and osteoporosis among Turkish women aged $52.9 \pm 4.7$ years to be $39.2 \%$ and $16.2 \%$ respectively ${ }^{16}$. Regarding studies in Saudi Arabia, similar high prevalence of both osteopenia and osteoporosis were reported, particularly among old-aged females. DesoukiM estimated the prevalence of osteopenia and osteoporosis in post-menopausal Saudi women aged $50-80$ years to be $31 \%$ and $40 \%$ respectively ${ }^{10}$.

In this study there was no osteoporosis, and osteopenia present in $11.25 \%$ of women. This may be due to higher level of knowledge among doctors about nutrition, good health status, less suffering from diseases, better economic condition, active life and enough sun exposure.

Adequate nutrition and active life play important roles in bone mass accrual and maintenance. It prevents fractures in individuals with osteoporosis. Not only calcium but also protein, phosphorus, magnesium, vitamin $D$ and potassium intakes are important factors related to bone health ${ }^{15}$.

According to World Health organization (WHO) data osteoporosis belongs to the three top prevailing pathologies together with cardiovascular diseases and diabetes ${ }^{16}$. Bone fractures are the clinical consequences of osteoporosis. In addition to increased mortality, fractures are associated with acute and chronic pain, disability, reduced quality of life and significant economic expenses and psychosocial problems ${ }^{16,17}$. Prevention of bone loss is easier than to restore it, so osteoposis's forecasting an early diagnosis is actual medical and social task ${ }^{17}$. 


\section{Conclusion \& Recommendation}

This study showed that most of the doctors of the study group had normal BMD though (11.25\%) had osteopania who are at risk of osteoporosis and fracture in future and vulnerable age group was 4564 years. In addition to continue their physical activity level, female doctors should enhance physical exercise and healthy food habit.

\section{References}

1. Mahboub SM, Al-MuammarMN, ClarifyAA .Evaluation of the Prevalence and Correlated Factors for Decreased Bone Mass Density among Pre- and Post-menopausal Educated Working Women in Saudi Arabia. J Health PopulNutor 2014 Sep; 32 (3): 513-519.

2. Tenenhouse A, Joseph L, Kreiger N, Poliquin S, MurrayT M, BlondeauL, BergerC, HanleyDA, PriorJC, and the CaMos Research Group. Estimation of the Prevalence of Low Bone Density in Canadian Women and Men Using a Population-Specific DXA Reference Standard: The Canadian Multicentre Osteoporosis Study (CaMos). OsteoporosInt(2000) 11:897-904.

3. SirisES \& SimonJA\& BartonIP\& McClung MR\&Grauer A. Effects of risedronate on fracture risk in postmenopausal women with osteopenia. OsteoporosInt (2008) 19:681-686.

4. Looker AC, Melton LJ, 3rd, Harris TB, Borrud LG, Shepherd JA. Prevalence and trends in low femur bone density among older US adults: NHANES 2005- 2006 compared with NHANES III. J Bone Miner Res 2010; 25:64-71.

5. Kleerekoper M, Al-Khayer F. Osteoporosis, overview. Encyclopedia Endocr Dis 2004; 3:425-31.

6. Keramat A, Patwardhan B, Larijani B, Chopra A, Mithal A, Chakravarty D et al. The assessment of osteoporosis risk factors in Iranian women com- pared with Indian women. BMC MusculoskeletDisord2008;9:28. doi: 10.1186/ 1471-2474-9-28.

7. Parfitt AM. Trabecular bone architecture in the pathogenesis and prevention of fracture. $A m \mathrm{~J}$ Med, 82(1B), pp. 68-72, 1987.

8. SiffertRS, Luo GM, Cowin SC, Kaufman JJ. Dynamical relationships of trabecular bone density, architecture and strength in a computational model of osteopenia. Bone, 18(2), pp. 197-206, 1996.

9. Jonathan J. Kaufman, GangmingLuo, David Conroy, William A. Johnson, Ronald L. Altman, Robert S. Siffert.New Ultrasound System for BoneAssessment.

10. El-Desouki MI. Osteoporosis in postmenopausal Sau- di women using dual x-ray bone densitometry. Saudi Med J 2003; 24:953-6.

11. Wasnich RD, Ross PD, Heilbrun LK, Vogel JM.Prediction of postmenopausal fracture risk with use of bone mineral measure- ments. Am J ObstetGynecol 1985;153:745.

12. Cummings SR, Black DM, Nevitt MC, Browner WS, Cauley JA, Genant HK, et al. Appendicular bone density and age predict hip fracture in women. The Study of Osteoporotic Fractures Research Group [see comments]. JAMA 1990; 263:665 \pm 8 .

13. Cummings SR, Nevitt MC, Browner WS, Stone $\mathrm{K}$, Fox KM, Ensrud KE, et al. Risk factors for hip fracture in white women. Study of Osteoporotic Fractures Research Group. N Engl J Med 1995; 332:767 \pm 73 .

14. Cheng S, Suominen H, Sakari-Rantala R, Laukkanen P, Avikainen V, Heikkinen E. Calcaneal bone mineral density predicts fracture occurence: a five-year follow-up study in elderly people. J Bone Miner Res 1997; 12:1075 \pm 82

15. Marcelo M Pinheiro, Natielen J Schuch, Patrícia S Genaro, Rozana M Ciconelli, Marcos B FerrazandLígia AMartini. Nutrient intakes related to osteoporotic fractures in men and women The Brazilian Osteoporosis Study (BRAZOS). Nutrition Journal 2009, 8:6 doi: 10.1186/14752891-8-6.

16. Demir B, Haberal A, Geyik P, Baskan B, Ozturkoglu E, Karacay $\mathrm{O}$ et al. Identification of the risk factors for osteoporosis among postmenopausal women. Matu- ritas2008; 60:253-6.

17. Ignatiev A. M., Turchin N. I., Yamilova T. N. Use of ultrasound densitometry for the assess of structural and functional disorders of bone tissue and prediction of fractures risk. Journal of Education, Health and Sport. 2015; 5(4):23-28. ISSN 2391-8306. 